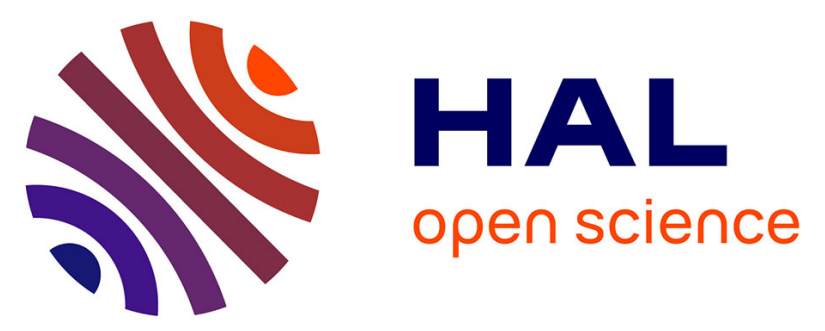

\title{
Low-noise cold-field emission current obtained between two opposed carbon cone nanotips during in situ transmission electron microscope biasing
}

Ludvig de Knoop, Christophe Gatel, Florent Houdellier, Marc Monthioux, Aurélien Masseboeuf, Martin Hÿtch, Etienne Snoeck

\section{To cite this version:}

Ludvig de Knoop, Christophe Gatel, Florent Houdellier, Marc Monthioux, Aurélien Masseboeuf, et al.. Low-noise cold-field emission current obtained between two opposed carbon cone nanotips during in situ transmission electron microscope biasing. Applied Physics Letters, 2015, 106 (26), pp.263101. 10.1063/1.4923245 . hal-01430586v2

\section{HAL Id: hal-01430586 \\ https://hal.science/hal-01430586v2}

Submitted on 23 Feb 2018

HAL is a multi-disciplinary open access archive for the deposit and dissemination of scientific research documents, whether they are published or not. The documents may come from teaching and research institutions in France or abroad, or from public or private research centers.
L'archive ouverte pluridisciplinaire HAL, est destinée au dépôt et à la diffusion de documents scientifiques de niveau recherche, publiés ou non, émanant des établissements d'enseignement et de recherche français ou étrangers, des laboratoires publics ou privés. 


\section{Low-noise cold-field emission current obtained between two opposed carbon cone nanotips during in situ transmission electron microscope biasing}

L. de Knoop, C. Gatel, F. Houdellier, M. Monthioux, A. Masseboeuf, E. Snoeck, and M. J. Hÿtch

Citation: Appl. Phys. Lett. 106, 263101 (2015); doi: 10.1063/1.4923245

View online: https://doi.org/10.1063/1.4923245

View Table of Contents: http://aip.scitation.org/toc/apl/106/26

Published by the American Institute of Physics

\section{Articles you may be interested in}

Development of an ultrafast electron source based on a cold-field emission gun for ultrafast coherent TEM Applied Physics Letters 111, 023101 (2017); 10.1063/1.4991681

Transmission type flat-panel X-ray source using $\mathrm{ZnO}$ nanowire field emitters

Applied Physics Letters 107, 243105 (2015); 10.1063/1.4938006

Temporal field emission current stability and fluctuations from graphene films

Applied Physics Letters 97, 062106 (2010); 10.1063/1.3474800

Field emission properties of carbon nanotubes

Journal of Vacuum Science \& Technology B: Microelectronics and Nanometer Structures Processing,

Measurement, and Phenomena 18, 665 (2000); 10.1116/1.591258

Field electron emission from pencil-drawn cold cathodes

Applied Physics Letters 108, 193112 (2016); 10.1063/1.4949563

Low p-type contact resistance by field-emission tunneling in highly Mg-doped $\mathrm{GaN}$

Applied Physics Letters 109, 252101 (2016); 10.1063/1.4972408

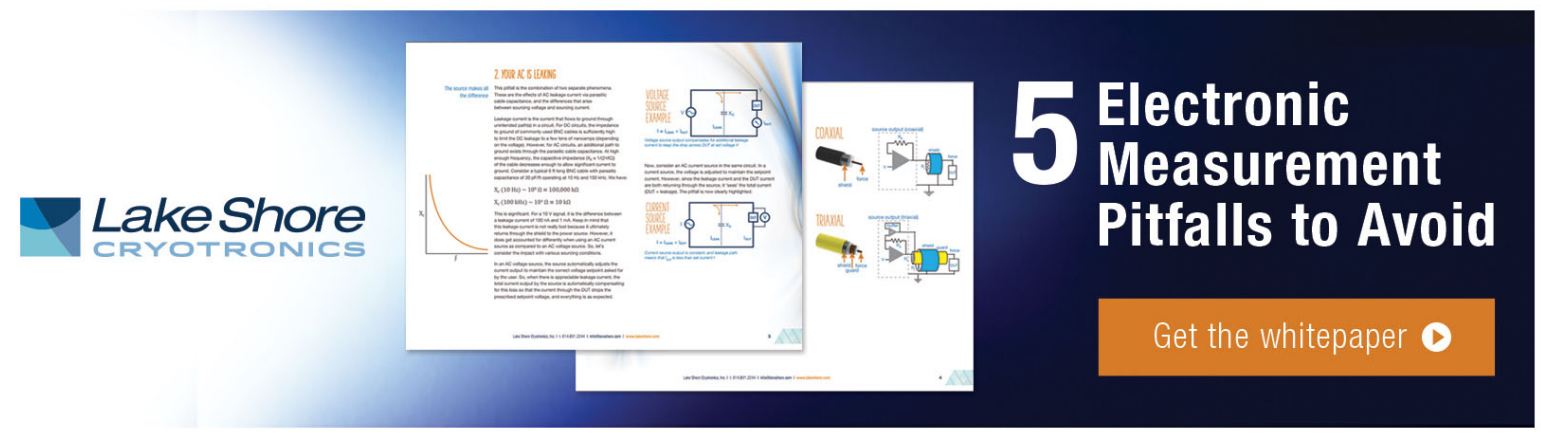




\title{
Low-noise cold-field emission current obtained between two opposed carbon cone nanotips during in situ transmission electron microscope biasing
}

\author{
L. de Knoop, C. Gatel, F. Houdellier, M. Monthioux, A. Masseboeuf, E. Snoeck, \\ and M. J. Hÿtch \\ CEMES, UPR-8011 CNRS, University of Toulouse, 29 rue Jeanne Marvig, 31055 Toulouse, France
}

(Received 9 April 2015; accepted 18 June 2015; published online 29 June 2015)

\begin{abstract}
A dedicated transmission electron microscope sample holder has been used to study in situ the cold-field emission process of carbon cone nanotips (CCnTs). We show that when using a CCnT instead of a Au plate-anode, the standard deviation of the emission current noise can be decreased from the $10 \mathrm{nA}$ range to the $1 \mathrm{nA}$ range under vacuum conditions of $10^{-5} \mathrm{~Pa}$. This shows the strong influence of the anode on the cold-field emission current noise. (C) 2015 AIP Publishing LLC.

[http://dx.doi.org/10.1063/1.4923245]
\end{abstract}

In an electron gun, the electron emission process can be either thermionic or field emission or a mix of both. Room temperature field emission, commonly named cold-field emission (CFE), is the brightest source available and also exhibits the smallest energy spread. ${ }^{1}$ The reduced brightness of commercially available CFE guns (CFEGs) is in the range of $10^{8} \mathrm{~A} \mathrm{~m}^{-2} \mathrm{Sr}^{-1} \mathrm{~V}^{-1}$. This value needs to be compared with the $10^{5} \mathrm{~A} \mathrm{~m}^{-2} \mathrm{Sr}^{-1} \mathrm{~V}^{-1}$ measured in a standard thermionic gun. Furthermore, the energy spread can be up to 10 times smaller with a CFEG compared with a thermionic gun. ${ }^{1}$

However, the CFEG suffers from two well-known drawbacks. First, the emission and the corresponding probe current noise remain high compared to a thermally-assisted source. This is mainly due to not only ion bombardment of the tip but also from atom migration across the cathode surface (known as flicker noise). ${ }^{2}$ Second, probe and emission current decrease over time with a continuous slope of between $10 \%$ and $20 \%$ per hour. This phenomenon is mainly due to the build-up of contamination on the emitter surface that disturbs the emission process. The corresponding slope in other electron sources is less than $1 \%$ per hour. $^{3}$

To improve the properties of a CFE electron source, experimentations have been made to exchange the standard $\mathrm{W}$ emitter tip with, e.g., multi-wall carbon nanotubes $(\mathrm{CNTs})^{4-8}$ (or carbon onions welded onto a $\mathrm{W}$ tip ${ }^{9}$ ). Due to the high aspect ratio and small tip radius of the structure, the electric field is strongly enhanced. Therefore, the extraction voltage for which the cold-field emission starts is smaller. The small tip radius increases the associated brightness of the source. ${ }^{7}$ Carbon is also chemically less reactive than $\mathrm{W}$, which reduces the contamination layer build-up on the surface, ideally resulting in lower noise and better current stability over time. ${ }^{10}$ Finally, the CNT high mechanical strength decreases the chance of structural failure that can arise from the extreme current density at the apex of the tip during field emission. ${ }^{6}$ Despite these superior properties, the continuation towards a commercial product has proven to be difficult. The reasons for this could be that the inherent high aspect ratio of CNTs causes them to vibrate upon electron emission, which degrades the emission properties like the brightness ${ }^{11}$ (unless they are shortened ${ }^{11,12}$ ). Additionally, due to their $\mathrm{nm}$ size, CNTs are difficult to handle, which makes the process of mounting time-consuming and unreliable.

We have earlier reported an alternative graphene-based carbon structure, the carbon cone nanotip (CCnT), which potentially could be implemented as a functional and easily installable cathode emitter in a CFE gun. ${ }^{13}$ The CCnT comprises a few $\mu \mathrm{m}$-wide and several $\mu \mathrm{m}$-long carbon fiber segment base, followed by an atomically smooth carbon cone whose apex has a tip radius of around $10 \mathrm{~nm}$ (see Figs. 1(b) and 1(c)). Because, alike CNTs, the cone part is also made from concentric graphene layers ${ }^{14}$ (the conical morphology being created by a progressive shortening of the widening tubes), this structure keeps all the desired properties of the $\mathrm{CNT}^{13}$ while at the same time minimizing any vibration and handling issues, because of its conical shape and large base. Recent results, where CCnTs have been used as emitting tips in various modern Hitachi CFE electron microscopes working at low $(30 \mathrm{kV})$ and high $(200 \mathrm{kV})$ acceleration voltage,
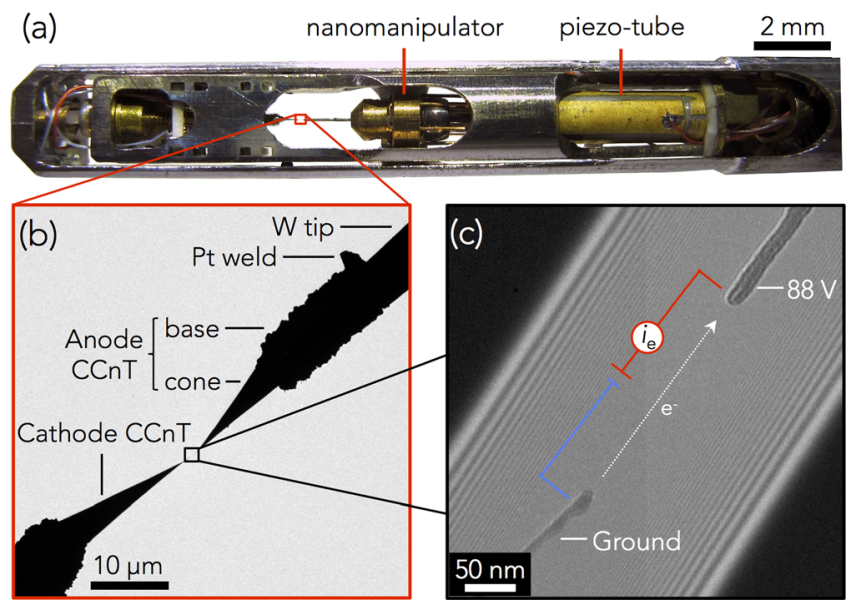

FIG. 1. (a) Front part of the TEM in situ biasing holder, with the nanomanipulator, driven by a piezo-tube. (b) A zoom-in of the two tips in the holder. (c) Further zoom-in and hologram of the two CCnTs, with the top one being biased and the lower one being ground. (the holographic measurements will be reported in a subsequent paper.) 
have revealed an unprecedented stability with almost no current decay during one hour. ${ }^{15}$

In situ transmission electron microscope (TEM) biasing experiments have also been performed to determine the CCnT exit work function. ${ }^{16}$ This was carried-out in a specialized TEM sample-biasing holder (see Fig. 1(a)) which enabled to field-emit electrons inside the sample holder while simultaneously observe and determine the electric field around the apex, using a combination of electron holography, the Fowler-Nordheim equations, and finite element method modeling. ${ }^{16}$

Around the sample holder inside the TEM column, where both experiments took place, the vacuum is in the order of $10^{-5} \mathrm{~Pa}$, whereas inside a CFE source it is around $10^{-9} \mathrm{~Pa}$ in order to maximize the current stability and minimize the noise. Indeed, a higher vacuum pressure, as well as a higher current, increases the noise and the current decay (as was reported by Todokoro $\mathrm{et} \mathrm{al}^{2}$ ). Therefore, the noise level on the $i_{\mathrm{e}} V$-curves measured during in situ field emission was high.

In this paper, we have performed the same experimental setup as in the paper mentioned above,${ }^{16}$ but using another $\mathrm{CCnT}$ as anode instead of a Au plate. We will show how this new configuration dramatically decreases the noise level of the emission current.

The sample preparation was carried out using a Cross Beam XB 1540 (Zeiss) focused ion-beam scanning electron microscope equipped with a gas-injection system and a microtweezer (Kleindiek) to manipulate the CCnTs. ${ }^{15}$ Electro-chemically etched W-tips were cut using the ion beam and a Pt-precursor of the gas-injection system was used to weld the CCnTs to the flattened W-tip apices (see Fig. 1(b)). The two CCnTs of this experiment had similar tip radii $(5-10 \mathrm{~nm})$ to the one used in the previous experiment. ${ }^{16}$ Furthermore, in both experiments, the vacuum was in the order of $10^{-5} \mathrm{~Pa}$. The CCnTs were inserted into a double-tilt in situ biasing TEM holder (Nanofactory Instruments) that allowed a potential of $\pm 140 \mathrm{~V}$ to be applied between the tips. A piezo-driven nanomanipulator allowed a long-range and precise positioning of the CCnTs inside the TEM (Fig. 1(a)). ${ }^{17}$ The separation distance between the two CCnTs was $220 \mathrm{~nm}$, whereas for the previous experiment, the distance between the $\mathrm{CCnT}$ and the plate-Au anode was $3.5 \mu \mathrm{m}$. Electron holograms were obtained using the SACTEMToulouse, an image-corrected (CEOS) Tecnai F20 (FEI) with a rotatable biprism and Schottky FEG. Phase analysis of the holograms will be reported in a different paper.

Due to the high vacuum pressure, $i_{\mathrm{e}} V$-curves obtained under the same conditions can differ significantly. So in order to be able to quantitatively compare the noise level, numerous current as a function of voltage $\left(i_{\mathrm{e}} V\right)$-curves were obtained. The noise was calculated based on these using the standard deviation, defined as below

$$
\sigma=\sqrt{\frac{\sum\left(i_{\mathrm{e}}-\bar{i}_{\mathrm{e}}\right)^{2}}{n}},
$$

where $i_{\mathrm{e}}$ is the field-emission current that is measured in the sample holder (see Fig. 1(c)), $\bar{i}_{\mathrm{e}}=\left(\sum i_{\mathrm{e}}\right) / n$ is the average current, and $n$ is the number of data points. Here, we calculated $\sigma$ for 6 data points, which corresponded to an increase of the potential of around $0.1 \mathrm{~V}$. This was done from 60 to $400 \mathrm{nA}$ on the $i_{\mathrm{e}} V$-curves. The $i_{\mathrm{e}} V$-curves differed somewhat in resolution for data points per volt and a larger voltage-span means a larger current-span and thus a higher value of $\sigma$. So in order to be able to compare $\sigma$ for different $i_{\mathrm{e}} V$-curves, the slope, which can be assumed to be linear during the $0.1 \mathrm{~V}$ increase, was removed using linear regression analysis.

For each bundle of 6 data points, the linear regression analysis resulted in an equation of the form $f(x)=\alpha x+\beta$, which describes the slope over this area. To obtain the standard deviation, $\beta$ is not needed. For $\alpha$, the following formula was exploited:

$$
\alpha=\frac{n \sum\left(V i_{\mathrm{e}}\right)-\sum V \sum i_{\mathrm{e}}}{n \sum V^{2}-\left(\sum V\right)^{2}},
$$

where $V$ is the applied potential and as before, $n=6$. Having $\alpha$, the linear slopes could be subtracted in order to obtain horizontal data slopes and then the standard deviation values were determined using Eq. (1). The linear regression analysis also provided quantitative data of the noise level since $\sigma$ was calculated on a non-inclined slope. For each $i_{\mathrm{e}} V$-curve, an average value $\bar{\sigma}=\left(\sum \sigma\right) / m$ was obtained (where $m \approx 70$ is the number of $\sigma$ obtained per curve). In total, $21 i_{\mathrm{e}} V$-curves where analyzed ( 12 for the plate-anode and 9 for the tipanode case). In Table I, the average value of $\bar{\sigma}$ for all $i_{\mathrm{e}} V$ curves can be seen. The table also shows an averaged value of $\bar{\lambda}$, which displays the fraction of the current that is noise, i.e.,

$$
\lambda=\frac{\sigma}{\bar{i}_{\mathrm{e}}},
$$

where $\bar{i}_{\mathrm{e}}=\sum i_{\mathrm{e}} / n, n=6$, and similarly as for the standard deviation, $\bar{\lambda}=\left(\sum \lambda\right) / m$, with $m \approx 70$. As can be seen in Table I, there is a remarkable around 6.4 times decrease in the noise when using a tip-anode instead of a plate-anode.

To illustrate this variance, two $i_{\mathrm{e}} V$-curves can be seen in Fig. 2, where (a) is for a plate-anode and (b) is for a tipanode case.

The zoom-in over $1 \mathrm{~V}$ provides a more detailed view of the curves. The inset in Fig. 2(a) shows an area of the curve where the noise is significantly smaller than its average. For Fig. 2(a), $\bar{\sigma}=4.3 \mathrm{nA}$ and $\bar{\lambda}=2.6 \%$ and for Fig. 2(b), $\bar{\sigma}=0.4 \mathrm{nA}$ and $\bar{\lambda}=0.2 \%$. These values can be compared with the average values in Table I of $14.3 \mathrm{nA}$ and $6.9 \%$ for the plate-anode and $2.2 \mathrm{nA}$ and $1.1 \%$ for the tip-anode.

As concluded by Todokoro et al., ${ }^{2}$ the main reason for the flicker noise comes from ion bombardment. Electrons that are emitted impinge the anode, causing desorption of

TABLE I. Average values of $\bar{\sigma}$ (standard deviation of the current) and $\bar{\lambda}$ (fraction of the current that is noise) of in total $21 i_{\mathrm{e}} V$-curves.

\begin{tabular}{lcc}
\hline \hline & Average of $\bar{\sigma}$ & Average of $\bar{\lambda}$ \\
\hline Plate-anode & $14.3 \mathrm{nA}$ & $6.9 \%$ \\
Tip-anode & $2.2 \mathrm{nA}$ & $1.1 \%$ \\
Difference & 6.5 times & 6.3 times \\
\hline \hline
\end{tabular}


(a)

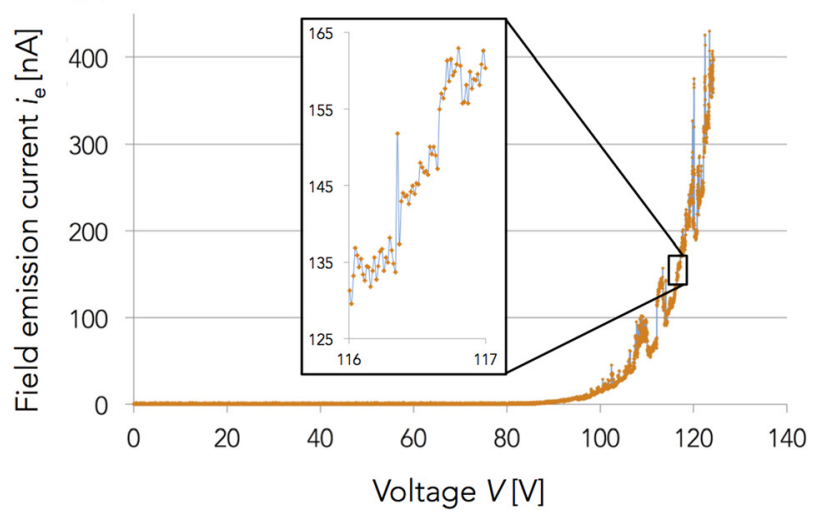

(b)

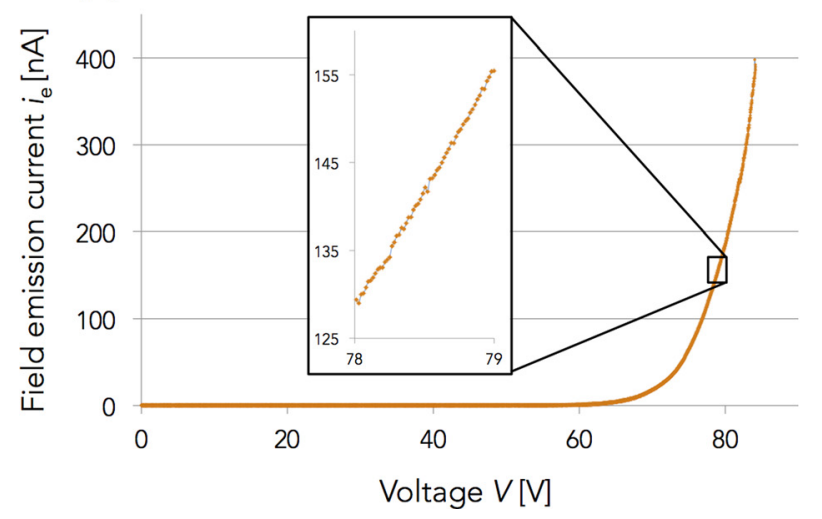

FIG. 2. Cold-field emission $i_{\mathrm{e}} V$-curves. In (a), a Au plate-anode was used, whereas in (b) the anode was a carbon cone nanotip. The purpose of the zoom-ins is to emphasize the higher noise for the former case. The standard deviation for the curve in (a) was $\bar{\sigma}=4.3 \mathrm{nA}$, and for (b), $\bar{\sigma}=0.4 \mathrm{nA}$.

molecules that are attached by van der Waals forces (sometimes called anode degassing). Subsequently, emitted electrons ionize these gas molecules, which results in the ions bombarding the negatively charged emitter, thus increasing the emission current noise.

In this experiment, when exchanging the plate-anode with a tip-anode, we observed a strong decrease in the field emission current noise even at low vacuum pressure. The reason for this effect comes from the electric field lines that are strongly focused not only at the cathode tip but also at the anode tip. Thus, the emitted electrons are impinging on an extremely reduced area when compared with the plateanode, which leads to less surface gas molecules being desorbed and thus less ions being created and bombarding the emitter. Furthermore, with such a small electron impact-area on the anode tip, the surface could be cleansed by the electron bombardment (which is a technique used to, e.g., clean the anode in some commercial CFE sources ${ }^{18}$ ) thus resulting in lower noise.

Simulations using the finite element method showed that the electric field around the cathode emitter obtained for a certain extraction voltage $V$ is $45 \%$ smaller when using a tipanode instead of a plate-anode. According to the simulations, the electric field for the tip-anode case on a mesoscopic level-i.e., without taking into account atomistic variations on the emitter surface-was around $6 \mathrm{~V} / \mathrm{nm}$ at the cathode tip (see Ref. 16). If the plate-anode had been at the same distance from the cathode as the tip-anode, the field and therefore the current would have been higher. But, as mentioned above, an increase in current increases the noise. ${ }^{2}$ Therefore, we have compared the noise for the same current (60-400 nA) for all $i_{\mathrm{e}} V$-curves but thus with different separation distances. The distance between the two CCnTs was $220 \mathrm{~nm}$, whereas in the plate-anode case the separation distance was $3.5 \mu \mathrm{m}$. The smaller distance for the tip-anode case should increase the noise, as anode degassing occurs closer to the emitter tip thus increasing the background pressure. In other words, the effect of a decrease in noise from using a tip-anode instead of a plate-anode might be even higher than what we have reported here.

In the experiment from Fig. 2(a), the plate-anode was made from $\mathrm{Au}$ and in the experiment from Fig. 2(b) not only was the shape different but also the material, as the CCnT is made out of carbon. How could this affect the noise level? The low reactivity of carbon is as stated above, one of the reasons this material is a good candidate to substitute the standard W tips as cold-field emitter tips. However, Au is a noble metal and possibly less reactive than graphenic $\mathrm{C}$. Therefore, if this is the case, the decrease in noise level could be even larger than what we have seen here. If such an effect exists and if it is measureable will be verified in future experiments.

In our previous study, we have demonstrated how the use of a CCnT as a FE cathode inside a state-of-the-art electron source, can decrease the current decay usually observed in $\mathrm{W}$ based technology by a factor of $10 .{ }^{15}$ Here, we have studied the origin of the emission current noise. We have shown how the standard deviation noise can be decreased from the $10 \mathrm{nA}$ range to the $1 \mathrm{nA}$ range by using a CCnT as extracting anode. Combining these two results, it seems possible to obtain a CFE electron source that would be a serious competitor to the Schottky field emission source regarding the beam stability, ${ }^{19}$ while keeping the highest brightness. This "ideal" source could also be operated under worse vacuum condition when compared to standard CFEGs, where the required $10^{-9} \mathrm{~Pa}$ range usually makes them difficult to use. A decrease to the $10^{-7} \mathrm{~Pa}$ range, for example, could considerably simplify their practical use. In order to tackle this challenge, and with the help of previous results, we are now studying new anode concepts in order to minimize the beam noise while keeping the geometrical aberrations of the source constant.

In this work, continuous $i_{\mathrm{e}} V$-curves were acquired, which required the noise-level calculations to be performed over a very short time-span. Naturally, it would be interesting to do the same comparison for data obtained during a longer period of time (that is, hours instead of seconds). The $i_{\mathrm{e}} V$-curves were also analyzed using Fowler-Nordheim equations. $^{20}$ This, together with results showing the fieldemission behavior when the potential over the two CCnTs was reversed, will be reported in a different paper.

The authors acknowledge the European Integrated Infrastructure Initiative Reference 312483-ESTEEM2, the French "Investissement d'Avenir" Program Reference No. ANR-10-EQPX-38-01, and the French ANR-Emergence Program ANR-12-EMMA-0044-01 for partial funding. 
${ }^{1}$ P. W. Hawkes and J. C. H. Spence, Science of Microscopy (Springer, 2007), Vol. XVIII.

${ }^{2}$ H. Todokoro, N. Saitou, and S. Yamamoto, Jpn. J. Appl. Phys., Part 1 21, 1513 (1982).

${ }^{3}$ D. B. Williams and C. B. Carter, Transmission Electron Microscopy (Springer, 2009).

${ }^{4}$ A. G. Rinzler, Science 269, 1550 (1995).

${ }^{5}$ J. M. Bonard, J.-P. Salvetat, T. Stöckli, L. Forro, and A. Châtelain, Appl. Phys. A 69, 245 (1999).

${ }^{6}$ Y. Saito and S. Uemura, Carbon 38, 169 (2000).

${ }^{7}$ N. de Jonge, Y. Lamy, K. Schoots, and T. H. Oosterkamp, Nature 420, 393 (2002).

${ }^{8}$ J. M. Bonard, K. Dean, B. Coll, and C. Klinke, Phys. Rev. Lett. 89, 197602 (2002)

${ }^{9}$ M. S. Wang, D. Golberg, and Y. Bando, ACS Nano 4, 4396 (2010).

${ }^{10}$ W. A. de Heer, A. Châtelain, and D. Ugarte, Science 270, 1179 (1995).

${ }^{11}$ E. C. Heeres, T. H. Oosterkamp, and N. de Jonge, Nanotechnology 22, 235308 (2011)
${ }^{12}$ J. H. Hafner, C.-L. Cheung, T. H. Oosterkamp, and C. M. Lieber, J. Phys. Chem. B 105, 743 (2001).

${ }^{13}$ F. Houdellier, A. Masseboeuf, M. Monthioux, and M. J. Hÿtch, Carbon 50, 2037 (2012)

${ }^{14} \mathrm{H}$. Allouche and M. Monthioux, Carbon 43, 1265 (2005).

${ }^{15}$ F. Houdellier, L. de Knoop, C. Gatel, A. Masseboeuf, S. Mamishin, Y. Taniguchi, M. Delmas, M. Monthioux, M. J. Hÿtch, and E. Snoeck, Ultramicroscopy 151, 107 (2014).

${ }^{16}$ L. de Knoop, F. Houdellier, C. Gatel, A. Masseboeuf, M. Monthioux, and M. Hÿtch, Micron 63, 2 (2014).

${ }^{17}$ K. Svensson, Y. Jompol, H. Olin, and E. Olsson, Rev. Sci. Instrum. 74, 4945 (2003)

${ }^{18}$ N. Dellby, N. J. Bacon, P. Hrncirik, M. F. Murfitt, G. S. Skone, Z. S. Szilagyi, and O. L. Krivanek, Eur. Phys. J.: Appl. Phys. 54, 33505 (2011).

${ }^{19}$ L. W. Swanson and G. A. Schwind, Handbook of Charged Particle Optics (CRC Press, New York, 1997), pp. 77-102.

${ }^{20}$ R. H. Fowler and L. Nordheim, Proc. R. Soc., London Ser. A 119, 173 (1928). 